\title{
Vectors and Valences: The Role of Digital Media in the Lives of Russian Queer Men
}

Tudor, Matilda. 201 8. Desire Lines: Towards a Queer Digital Media Phenomenology. PhD diss. Södertörn University: Media and Communication Studies. (280 pages)

IN DESIRE LINES: Towards a Queer Digital Media Phenomenology, Matilda Tudor undertakes an examination of queer men's lives in St. Petersburg, Russia. The second largest city after Moscow, St. Petersburg has historically been considered more liberal than other cities, including the nation's capital. At the same time, the recent murder of Yelena Grigoryeva, a prominent LGBT activist who lived in the city, serves as a reminder that any such claim to liberalism should only be understood as comparative in a country that continues to deny LGBTQ people basic human rights. Stories of discrimination and persecution against queer Russians regularly circulate in the international press and on social media, and it is within this broader context of judicial and extra-judicial homophobia and transphobia that Tudor's study is situated. For a study such as Desire Lines, then St. Petersburg might best be understood as offering slightly easier access to research participants and an LGBTQ subculture, within a context that remains far from accepting of queer lives. 
Utilising ethnographic methods and queer theory to develop a critical reading of queer life in and around Russia's second city, Tudor sets out to explore the ways in which queer Russian men use digital media technologies in their exploration of same-sex desire and identity. However, as she explains in the introductory chapter, the digital is "decentred" in this project, situated within a broader landscape of media use, social relations, and everyday life. This has the effect of positioning gay/queer digital environments as a part of the story, but not the whole story: the digital thus becomes a doorway into the lives of these men, rather than a destination, solution or endpoint.

These metaphors of movement and space are apt for a project that employs themes of space, place, im/mobility, and wayfinding, which draws on the work of Shaun Moores, Sarah Ahmed, Maurice Merleau-Ponty, Henri Lefebvre, and Doreen Massey. Following an introductory chapter, three contextual chapters map out the historical, theoretical, and methodological frameworks that underpin this research (including the development of a "fag-hag" ethnography). We are then introduced to the nineteen participants who informed Tudor's work and it is their stories that structure the ensuing analysis chapters.

In chapter five, "A Queer Kind of Dwelling," Tudor focuses on the early lives of the participants, identifying the sense of "placelessness" that queer men experience when growing up in a heteronormative context. The chapter identifies the discursive absence of homosexuality in Russian society; an absence that often means same-sex desire simply does not exist. This assertion allows the author to utilise a phenomenological framework to explore the "disorientation" that characterises the early lives of her informants. Into this disorientation, arrives the Internet and we learn that many of the study's informants began to find a sense of self - and a sense of place - online. Tudor identifies the power that comes from simply "seeing" that other queer people online are living in the same place as oneself. As such, the Internet is conceptualised less as a space one escapes to, and more as a tool that re/locates and opens up new trajectories in physical environments. 
The sixth chapter moves us into the contemporary world of the informants, highlighting a uniquely Russian interpretation of public and private life, informed by Soviet history and post-Soviet society. Digital media play a key role in the negotiation of public and private life here, creating private spaces on what are typically considered public platforms. For instance, we learn of participants resisting social media "context collapse" (the accidental bringing together of different spheres of one's life - friends, family, work colleagues) by creating dual profiles on VKontakt, the popular Russian social media platform. One profile affords them a queer life online, and one affords a "regular" life. Forgoing the invitation to organise these in a hierarchy, or to see one profile as more authentic than the other, the author argues that these digital "faces" allow participants to inhabit whole selves - to be "complete." This insight challenges not only the binaries of Western thinking, but also points towards a "queer" form of integration: an orientation towards different aspects of one's life that accommodates societal pressures, family needs, and personal desires.

In chapter seven, we learn of another instance where Russian digital culture differs from European or North American contexts. Drawing on her interview material, the author identifies how the arrival for geolocative technologies (such as the dating application, Grindr) neither negated, nor de-prioritised older platforms used by queer men to meet one another offline. Indeed, while Grindr provides an opportunity to "queer" one's immediate environment, it becomes clear that the much older, anonymous BBS systems offer a more reliable method for hooking up. One gets the sense in this chapter that the informants find something exciting, unknown, and veiled about this older form of interacting. This of course speaks to older forms of queer life, but it is not the same as that older life and the dissertation articulates the knowledge and knowingness of the interviewees. What the reader witnesses then, is not a "return" to cruising, but an evolution of it.

The final analysis chapter focuses on a temporality that has lately occupied Western queer intellectuals, but which has always influenced the lives of queer people, that of the future. Tudor examines the multiple 
ways her research participants speak of the future and such talk of "tomorrow" invariably offers further insights into the context of "today." For some participants, the future is an abstract im/possibility marked as a non-existent place that throws into relief the complexities of the present. It is at this point in the dissertation that we hear the most vocal dissent towards Western understandings of sexual identities. Some participants call into question the fixed status of a "gay identity," which appears to foreclose possible futures they are unwilling to let go of. Better, instead to linger in the present - no matter how challenging that might be - than to determine a future that seemingly demands a disinvestment in other possibilities.

Juxtaposed to this "lingering in the present" is a second category of participants, who engage in, what Tudor terms, "digital migration." Here, new horizons and new possibilities are opened up through connections with a transnational network of queer folk. "Digital migration" is used to signpost (and facilitate) a movement out of Russia - even when the participant remains physically in St. Petersburg. Hence, for some participants, their queer selves have in a sense already (perhaps have always) existed outside of Russia - located in other places (be they physical or immaterial).

The concluding chapter offers a critical reflection that brings together the multifarious findings established therein. It signposts the fact that queer people forge existences in multiple ways, using a variety of resources in order to fully extend themselves, and develop desire lines that allow them to take up and occupy space. Digital technologies of communication play a key role in this process. Tudor $(2018,237)$ writes: "Queer digital media use re-organises and co-produces senses of space, time and queer being in contemporary Russia." For many of those involved in this project, it allows for the occupation of local space - a way of being within the proximate world - while simultaneously offering lines of flight; trajectories and mobilities that allow queer folk to "walk off the line" and create their own ways of being in the present, past and future.

Desire Lines is thought-provoking, methodologically intelligent, and critically rigorous, offering scholars valuable new insights into the use 
of digital media by queer folk. At the same time, it critiques normative understandings of queer identity, queer space, and queer media and promotes a culturally-specific approach to studying digital media practice.

SHARIF MOWLABOCUS FORDHAM UNIVERSITY 